\title{
Effectiveness of a Faculty Development Course on Delivering Learner-Centered Feedback Utilizing the Flipped Training Model
}

\author{
Brandy Church, MA 1 , William D. Corser, PhD, RN¹, Angela Harrison ${ }^{1}$ \\ ${ }^{1}$ Michigan State University Statewide Campus System, College of Osteopathic Medicine, East Lansing, MI 48824 \\ Keywords: flipped training model, faculty resident supervision, resident feedback \\ https://doi.org/10.51894/001c.6514
}

\section{Spartan Medical Research Journal}

Vol. 3, Issue 1, 2018

\begin{abstract}
CONTEXT
Effective feedback is an important step in the acquisition of residents' clinical skills and a key component of most adult learning strategies. Faculty-resident feedback discussions can facilitate resident self-assessment and reflection on their performance and motivate them to study and ask questions in areas where their knowledge may be evaluated as deficient. The flipped training model approach, a type of blended learning that reverses the traditional learning environment by delivering instructional content outside of the classroom, has garnered increased support within both graduate medical education (GME) and other healthcare disciplines.
\end{abstract}

\section{METHODS}

The overall purpose of this exploratory pilot project was to examine the pre-post impact of a faculty feedback flipped training model course provided to a convenience sample of community-based faculty learners. After receiving campus IRB approval, the authors developed a set of five primary course goals and objectives. A convenience sample of $n=$ 17 community-based faculty who had completed the entire course were administered a pair of pre and post-course surveys regarding their overall feedback satisfaction and comfort levels for supervising residents.

\section{RESULTS}

In summary, five of the 13 total survey items increased at statistically significant levels from pre-course levels. The majority of qualitative faculty comments also positively evaluated the flipped training model approach.

\section{CONCLUSIONS}

These promising pilot findings suggest that a flipped GME faculty feedback skills training model can help improve faculty learners' satisfaction and confidence as they supervise residents and/or medical students. The impact of these types of flipped training models for GME faculty needs to be more rigorously examined in project settings with larger samples to identify what specific types of curricular activities might prove to be most effective for diverse faculty learners in GME programs across the nation.

\section{INTRODUCTION}

Resident physicians frequently learn through direct clinical encounters with patients under faculty supervision. ${ }^{1}$ As such, faculty feedback concerning resident performance is a critical element of their professional development. ${ }^{1}$ Effective faculty feedback helps residents improve professional behaviors and performance to meet residency program objectives. ${ }^{1}$ In fact, current Accreditation Council for Graduate Medical Education (ACGME) accreditation standards emphasize the necessity of direct trainee observation and provision of timely faculty feedback. ${ }^{1}$

Effective feedback is an important step for residents to acquire clinical skills and a key component of most adult learning strategies. ${ }^{2}$ Faculty-resident feedback discussions can facilitate resident self-assessment and motivate them to study in areas where their knowledge has been evaluated as deficient. ${ }^{2}$ Without effective feedback, residents' medical care mistakes may go uncorrected without reinforcing their good clinical performance. ${ }^{3,4}$

Studies have indicated that the impact of faculty feedback messages is often related to the manner in which the feedback was provided. ${ }^{5-7}$ Feedback confined to an explanation of what practices should be changed can have minimal impact on subsequent behaviors. ${ }^{8-10}$ Specific suggestions concerning how to improve/modify practice activities or recommendations regarding the acquisition of a new skill, however, can lead to longer-term improvements in 
both learner knowledge and skill levels. ${ }^{10,11}$ On the other hand, ineffective feedback can cause learners to feel personally assaulted, or that their thoughts, opinions, and ideas are being ignored/slighted, frequently leading to defensiveness. ${ }^{12,13}$

The truth is that medical trainees in graduate medical education (GME) environments more often desire honest faculty feedback. For example, a study of over 1,500 residents found that $96 \%$ of respondents believed that instructor feedback was an important part of their learning, although most residents described their having received feedback as uncommon. ${ }^{8}$ During another study, residents indicated that feedback typically just reinforced positive behaviors or skill performance, rather than providing them constructive information for areas needing improvement. ${ }^{9}$ In this study, $80 \%$ of resident respondents indicated that they had either infrequently or never received corrective feedback. This finding indicates that there may be a compelling need to improve how residents are provided feedback in many GME settings. ${ }^{9}$

The flipped training model approach, a type of blended learning that reverses traditional didactic learning techniques with delivering online content before classroom activities, has garnered increased support in GME and other healthcare disciplines. ${ }^{14-17}$ Using this type of training approach, learners generally complete online content traditionally delivered in classroom lecture sessions to practice applying these concepts during classroom activities rather than completing it as assigned "homework."

\section{PROJECT PURPOSE}

The overall purpose of this exploratory pilot project was to examine the pre-post course impact of a faculty feedback flipped training model course provided to a convenience sample of community-based faculty learners.

\section{METHODS}

After receiving campus IRB approval, the authors, all employed by the Michigan State University Statewide Campus System (SCS) ${ }^{18}$ developed a set of five primary course goals and objectives for faculty participants to learn principles of providing effective learner-centered feedback to residents. These objectives included: a) describing why feedback is important for resident development; b) identifying key elements of effective feedback messages; c) describing proven strategies to provide feedback in GME settings; d) applying these principles during various teaching scenarios; and e) adapting popular feedback approaches to help create dynamic faculty-resident feedback discussions. A Feedback Course Committee consisting of three practicing clinicians and two $\mathrm{PhD}$ educators had consulted with the authors to make developmental curricular improvements. (Acknowledgements Section)

To meet the course objectives, the authors formulated faculty learner self-assessments and summative course evaluations aligned to each of the different objectives. Using Bloom's taxonomy, ${ }^{19}$ the authors identified which objectives could be adequately covered by the online course content assignments. The authors then worked with the ed- ucator consultants to designate the objectives associated with higher-level (e.g., application, synthesis, evaluation) observable behaviors for the hands-on classroom workshop.

The online course objectives and assessments were used to create an online course using the Desire2Learn learning management software. ${ }^{20}$ This part of the course contained a series of 10-12-minute snippets of content regarding how to provide learner-centered feedback, relevant literature concerning the topic, as well as video segments for feedback visualization.

After the online course components were finalized, the authors met with the University of Michigan's Center for Research on Learning and Teaching (CRLT) Players ${ }^{21}$ to plan the interactive workshop activities. This group of trained professional actors facilitated faculty development events to create instructor-learner cases during in-classroom faculty activities. During the workshop, the CRLT Players acted out resident feedback case scenarios and the authors asked faculty participants to provide feedback to the actors concerning their feedback behaviors and messages.

After the formulation of the online course and face-toface workshop were complete, approximately 2,000 SCSaffiliated core faculty, program directors, and directors of medical education were emailed course promotion materials. Nineteen $(0.95 \%)$ faculty completed the course registration process.

To evaluate the potential of the flipped training model approach to influence pre and post-course faculty learners' feedback satisfaction and confidence levels, the authors administered a hard copy of the earlier-validated Faculty Feedback Survey (FFS) ${ }^{7}$ before and after the course was completed. (Appendix 1) Along with a series of items asking respondents about their GME characteristics, the FFS was comprised of a series of 13 key Likert scale items asking respondents about their current level of satisfaction with their feedback skills and overall level of confidence providing residents with feedback.

The authors sent instructions regarding how to access the online course content. Two registrants failed to complete the online course and were not invited to the subsequent in-class workshop. Each of the remaining 17 registered participants attended the event and completed the post-course survey to measure any changes in their feedback knowledge attainment.

\section{RESULTS \\ DESCRIPTIVE STATISTICS}

A total sample of 17 faculty respondents completed over $95 \%$ of $\mathrm{FFS}^{7}$ survey items in both pre and post-course surveys. Nine (47\%) sample respondents reported their gender as Male, nine (47\%) participants were Female, and one (5\%) faculty reported their gender as Transgender at time of the post-course survey. Six faculty indicated that they had been supervising residents and/or medical students for between Zero and Five Years, with six reporting Six to Ten Years and the remaining respondents reporting 11 years or More. Only two (11\%) faculty indicated that they had received any prior formal feedback training. 


\begin{tabular}{|c|c|c|}
\hline & $\begin{array}{l}\text { Pre-Course Mean } \\
\text { (SD) (range) }\end{array}$ & $\begin{array}{l}\text { Post-Course Mean } \\
\text { (SD) (range) }\end{array}$ \\
\hline \multicolumn{3}{|c|}{$\begin{array}{l}\text { I. Summary Feedback Scores (possible range } 1 \text { Very Dissatisfied through } 5 \text { Very } \\
\text { Satisfied) }\end{array}$} \\
\hline Quality of (My) Feedback to Residents/Medical Students & $\begin{array}{l}3.47(\mathrm{SD} 0.624)(2 \\
\text { to } 4)\end{array}$ & $4.00(0.612)(3$ to 5$)$ \\
\hline Amount of (My) Feedback to Residents/Medical Students & $3.18(0.728)(2$ to 4$)$ & $3.76(0.903)(2$ to 5$)$ \\
\hline Timeliness of (My) Feedback to Residents/Medical Students & $3.47(0.717)(2$ to 5$)$ & $3.88(0.928)(2$ to 5$)$ \\
\hline \multicolumn{3}{|c|}{$\begin{array}{l}\text { II. Individual Feedback Satisfaction Scores (possible range } 0 \text { Poor through } 5 \\
\text { Excellent) }\end{array}$} \\
\hline 1. "Quality of (My) Positive Feedback" & $4.00(0.730)$ & $4.25(0.577)$ \\
\hline 2. "Quality of (My) Constructive Criticism" & $3.31(0.704)$ & $3.69(0.793)$ \\
\hline 3. "Quality of Feedback regarding Medical Knowledge" & $3.14(0.770)$ & $3,57(0.646)$ \\
\hline 4. "Quality of Feedback re: Communication Skills" & $3.27(0.961)$ & $3.87(0.915)$ \\
\hline 5. "Quality of Feedback re: Professionalism" & $3.27(0.961)$ & $3.73(0.961)$ \\
\hline 6. "Quality of Feedback re: Procedural Skills" & $3.27(1.104)$ & $3.82(1.178)$ \\
\hline 7. "Quality of Feedback re: Documentation" & $3.46(0.967)$ & $3.85(0.801)$ \\
\hline 8. "Quality of Feedback re: Evidence-Based Decision making" & $3.47(0.834)$ & $3.73(0.961)$ \\
\hline \multicolumn{3}{|c|}{$\begin{array}{l}\text { III. Summary Comfort Scores (poss. range from } 1 \text { Extremely Uncomfortable } \\
\text { through } 8 \text { Extremely Comfortable) }\end{array}$} \\
\hline 1. "Comfort Providing Positive Feedback" & $6.29(1.359)$ (4 to 8$)$ & $6.59(0.030)(5$ to 8$)$ \\
\hline 2. "Comfort Providing Constructive Criticism" & $5.18(1.629)(2$ to 8$)$ & 6.00 (1.414) (3 to 8) \\
\hline
\end{tabular}

Two (11\%) faculty indicated before the course that they "rarely" ever provided such feedback to residents/students, four (21\%) indicated Not Every Day to this survey item, with the remaining 11 (58\%) of faculty indicating Not Every Day but Every 2 to 5 Days. A total of 15 (88\%) of sample faculty indicated that they had generally "enjoyed providing feedback" to residents/medical students.

Each of the 17 survey respondents indicated at least two "barriers" to their providing either positive feedback and/or constructive criticism to residents/students (from a total of 12 provided barriers). The Mean number of barriers reported by participants was 3.94 (SD 1.89) and ranged from two to seven. Cited barriers included: a) Don't Feel Skilled at Giving Feedback. $(\mathrm{n}=6), \mathrm{b})$ Residents/medical students don't accept feedback well. $(\mathrm{n}=5), \mathrm{c})$ I don't want to harm my rapport with residents/students. $(\mathrm{n}=16), \mathrm{d})$ Time constraints. $(\mathrm{n}=11)$, e) I don't think of it during shift. $(\mathrm{n}=5)$ and $\mathrm{f})$ Lack of a Private Place to Talk. $(\mathrm{n}=4)$.

\section{PRE AND POST-COURSE SURVEY RESPONSE PATTERNS}

The analyst author (WDC) generated descriptive analyses of the working data set to evaluate appropriate analytic options and compare pre-to-post-course feedback response data. As might be readily expected from a smaller self-selected sample, he confirmed that the distribution of summary and individual $\mathrm{FFS}^{7}$ score patterns was not normally distributed. In response, a series of non-parametric Wilcoxon Matched Pair t test analytic procedures ${ }^{22}$ were completed using SPSS Version $22^{23}$ analytic software. The authors used these procedures to compare potential pre-post differences in individual-item and composite pre-post course respondent feedback satisfaction and confidence scores for statistical significance observing a two-tailed coefficient Alpha level of 0.05 .

\section{PRE-COURSE SURVEYS}

A total convenience sample of 17 faculty completed the $\mathrm{FFS}^{7}$ both before, and after they completed the flipped curriculum feedback course to be included in analyses. With regard to the three (i.e. quality of feedback (QF), amount of feedback (AF), timeliness of feedback (TF) "summary" feedback satisfaction items, the sample pre-course means were obtained: a) QF Mean 3.47 (SD 0.624), b) AF Mean 3.18 (SD 0.728), and c) TF Mean 3.47 (SD 0.717). (on possible five-point Likert scale from "1" ("Very Dissatisfied") to " 5 " ("Very Satisfied"). These initial findings demonstrated that the average course participant felt a moderate level of preworkshop satisfaction with the feedback patterns they currently provided residents and students. (See Table 1 for all summary and individual pre and post-course respondent scores).

The next eight individual pre-course feedback satisfaction item ratings data were fairly similar to the summary pre-course measures, (although each item on a five point "0" ("Poor") to "5" ("Excellent") scale). Participants' self-rating scores each averaged in the " 3 " (Good) or "4" ("Very Good") rating categories. Two remaining comfort survey items (on an eight-point Likert scale from “1” ("Extremely Uncomfortable") to "8" ("Extremely Comfortable") averaged 
Table 2: Pre and Post-Course Faculty Feedback Survey 7 Scores (N = 17 GME Faculty with complete data) *

\begin{tabular}{|c|c|c|c|c|c|}
\hline & $\begin{array}{l}\text { Pre-Course } \\
\text { Mean Score }\end{array}$ & $\begin{array}{l}\text { Post-Course } \\
\text { Mean Score }\end{array}$ & Difference & $\begin{array}{l}\text { Z } \\
\text { Score }\end{array}$ & Significance \\
\hline \multicolumn{6}{|l|}{$\begin{array}{l}\text { I. Summary Feedback Scores (poss. } \\
\text { range } 1 \text { through 5) }\end{array}$} \\
\hline 1. Quality of My Feedback & 3.47 & 4.00 & +0.529 & 2.729 & 0.015 \\
\hline 2. Amount of My Feedback & 3.18 & 3.76 & +0.588 & 2.582 & 0.020 \\
\hline 3. Timeliness of My Feedback & 3.47 & 3.88 & +0.412 & 2.135 & 0.049 \\
\hline \multicolumn{6}{|l|}{$\begin{array}{l}\text { II. Individual Feedback Satisfaction } \\
\text { Scores (poss. range } 0 \text { through 5) }\end{array}$} \\
\hline 1. Quality of (My) Positive Feedback" & 4.00 & 4.25 & +0.025 & 1.464 & 0.164 \\
\hline $\begin{array}{l}\text { 2. Quality of (My) Constructive } \\
\text { Criticism" }\end{array}$ & 3.31 & 3.69 & +0.375 & 2.087 & 0.054 \\
\hline $\begin{array}{l}\text { 3. Feedback regarding Medical } \\
\text { Knowledge" }\end{array}$ & 3.14 & 3.57 & +0.429 & 1.710 & 0.111 \\
\hline 4. Feedback re: Communication Skills" & 3.27 & 3.87 & +0.600 & 1.964 & 0.070 \\
\hline 5. Feedback re: Professionalism" & 3.27 & 3.73 & +0.467 & 1.974 & 0.068 \\
\hline 6. Feedback re: Procedural Skills" & 3.27 & 3.82 & +0.545 & 2.631 & 0.025 \\
\hline 7. Feedback re: Documentation" & 3.46 & 3.85 & +0.385 & 1.806 & 0.096 \\
\hline $\begin{array}{l}\text { 8. Feedback re: Evidence-Based } \\
\text { Decision making" }\end{array}$ & 3.47 & 3.73 & +0.267 & 1.468 & 0.164 \\
\hline \multicolumn{6}{|l|}{$\begin{array}{l}\text { III. Summary Comfort Scores (poss. } \\
\text { range } 1 \text { through } 8 \text { ) }\end{array}$} \\
\hline 1. Comfort Providing Positive Feedback & 6.29 & 6.59 & +0.294 & 1.429 & 0.172 \\
\hline $\begin{array}{l}\text { 2. Comfort Providing Constructive } \\
\text { Criticism }\end{array}$ & 5.18 & 6.00 & +0.824 & 2.190 & 0.044 \\
\hline
\end{tabular}

*Series of Wilcoxon Matched Pair Tests

Statistically Significant Differences at Alpha of less than 0.05 are listed in Bold font

slightly higher than the satisfaction items in the 5 or 6 categories. (Table 1).

\section{COMPARISON OF PRE-TO-POST-COURSE FEEDBACK SATISFACTION AND COMFORT LEVELS}

Each of the three (i.e. QF, AF, TF) pre-to-post-course feedback satisfaction ratings scores were found to have increased at statistically significant levels (t scores between $=2.135$ and 2.729, $\mathrm{p}$ values ranging from 0.015 to 0.049 ) . (Table 1). Overall, however, the majority of individual feedback satisfaction $(n=8)$ or comfort $(n=2)$ score increases failed to reach statistical significance except for one item (i.e., Quality of Feedback to Residents related to Procedural Skills) $(\mathrm{t}=2.631, \mathrm{p}=0.025)$. (Table 2)

Readers should note that only two of these eight individual survey items had complete participant data, indicating that respondents may have experienced some difficulty answering some of these items. In addition, one of the two final feedback comfort survey items with complete survey data (i.e. Overall Comfort with Providing Constructive Criticism) also increased significantly $(t=2.190, p=0.044)$ after the workshop. (Table 2) In summary, five of the 13 total postcourse survey items were shown to have increased at statistically significant levels from pre-course levels.

\section{POST-COURSE EVALUATIONS}

Eleven additional items in the post-course survey were included to ask respondents to evaluate different aspects of the on-line feedback and in-class workshop components of the curriculum. In summary, at least $64 \%$ of respondents reported either Agree or Strongly Agree when positively evaluating parts of the feedback course on a possible five point Likert-type scale from "1" "Strongly Disagree" to "5" "Strongly Agree" scale. Approximately five (26\%) participating faculty reported some degree of difficulty either accessing the online course and/or navigating online course content.

\section{DISCUSSION}

In summary, five of the 13 total post-course $\mathrm{FFS}^{7}$ survey items increased at statistically significant levels from precourse levels. Similar to several earlier GME studies, ${ }^{14,15,17}$ the majority of participating faculty comments also positively evaluated the flipped curriculum online content and workshop activities.

Readers should consider these initial pilot results within the context of several clear project limitations. The results came from a smaller convenience sample of 17 GME faculty 
who already appeared from pre-course survey responses to be fairly satisfied and/or comfortable with their resident feedback behaviors. The project was certainly likely underpowered to detect some meaningful pre-post-course sample subgroup differences (e.g. male versus female residents) that might be detectable in a larger diverse faculty sample. The authors acknowledge that measured increases in participants' feedback satisfaction and confidence ratings may have been somewhat skewed by some degree of Hawthorne/ observer effect since respondents knew their study responses would be reviewed by the authors.

\section{CONCLUSION}

These promising project findings suggest that a flipped GME faculty-training model may be useful to improve faculty feedback satisfaction and comfort when supervising residents and/or medical students. The full impact of these types of curricular models for GME faculty requires studies more rigorously examined in settings with larger samples to tease out what specific types of curricular activities might be most effective for the diverse faculty learners.

In hindsight, the authors could have more aggressively tried to address and discuss perceived barriers to providing resident feedback for faculty during the online pre-course training content. The authors could have also increased inclass feedback training activities to provide faculty with more opportunities to apply this content in a variety of hypothetical scenarios.

These measured improvements in faculty learners' perceived feedback satisfaction and comfort provide evidence suggesting that the more purposeful targeting and delivery of such educational curricula may contribute to community-based GME faculty development programs. Ideally, the curricular refinements developed from future studies will lead to improvements in the feedback patterns of GME faculty supervising residents and medical students across the nation.

\section{CONFLICT OF INTEREST}

The authors declare no conflict of interest.

\section{FUNDING}

The authors report no external funding source for this study.

\section{ACKNOWLEDGMENTS}

1. Dr. JoAnne Mitchell, DO, Director of Medical Education, McLaren Oakland, Pontiac, MI.

2. Dr. Saroj Misra, DO, St. John Macomb-Oakland Hospital, Warren, MI.

3. Dr. R. Taylor Scott, DO, Director of T3 Curriculum and Osteopathic Patient Care Longitudinal Series, MSU College of Osteopathic Medicine, East Lansing, MI.

4. Dr. Jonathan Rohrer, PhD, DMin, Associate Dean, Statewide Campus System, MSU College of Osteopathic Medicine, East Lansing, MI.

5. Dr. Margaret Kingry, PhD, Associate Professor, Department of Pediatrics, College of Osteopathic Medicine, Michigan State University, East Lansing, MI.

Submitted: November 15, 2017 EST, Accepted: March 15, 2018 EST 


\section{REFERENCES}

1. Holmboe ES, Ward DS, Reznick RK, et al. Faculty development in Assessment: The missing link in competency-based medical education. Acad Med. 2011;86(4):460-467.

2. Hueppchen NA. Preceptor Series: Providing Educational Feedback. Crofton, MD: Association of Professors of Gynecology and Obstetrics; 2013.

3. Pelgrim EAM, Kramer AWM, Mokkink HGA, van der Vleuten CPM. Factors influencing trainers' feedbackgiving behavior: A cross-sectional survey. BMC Med Educ. 2014;14(65).

4. Kraut A, Yarris LM, Sargeant J. Feedback: Cultivating a positive culture. J Grad Med Educ. 2015;7(2):262-264.

5. Sefcik D, Petsche E. The CAST model: Enhancing medical student and resident clinical performance through feedback. J Am Osteopath Assoc. 2015;115(4):196-198. https://www.ncbi.nlm.nih.gov/ pubmed/25830574.

6. Yarris LM, Linden JA, Hern HG, et al. Attending and resident satisfaction with feedback in the emergency department. Acad Emerg Med. 2009;16:S76-S81.

7. Yarris LM, Fu R, LaMantia J, et al. Effect of an educational intervention on faculty and resident satisfaction with real-time feedback in the emergency department. Acad Emerg Med. 2011;18:504-512.

8. Schultz KW, Kirby J, Delva D, et al. Medical students' and residents' preferred site characteristics and preceptor behaviors for learning in the ambulatory setting: A cross-sectional survey. BMC Med Educ. 2004;4(12).

9. Isaacon JH, Posh LK, Litaker DG, Halperin AK. Residents' perceptions of the evaluation process. J Gen Intern Med. 1995;10(Suppl):S89.

10. Ramani S, Krackov SK. Twelve tips for giving feedback effectively in the clinical environment. Med Teacher. 2012;34:787-791.

11. Wiliam D. What is assessment for learning? Studies Educ Eval. 2011;37:3-14.

12. Menachery EP, Knight AM, Kolodner K, Wright S. Physicians characteristics associated with proficiency in feedback skills. J Gen Intern Med. 2006;21:440-446.
13. Veloski J, Boex JR, Grasberger MJ, Evans A, Wolfson DB. Systematic review of the literature on assessment, feedback and physicians' clinical performance: BEME Guide No. 7. Medical Teacher. 2006;28(2):117-128.

14. Cooper AZ, Hsieh G, Kiss JE, Huang GC. Flipping out: Does the flipped learning model work for GME? J Grad Med Educ. 2017;9(3):392-393.

15. Young TP, Bailey CJ, Guptill M, Thorp AW, Thomas TL. The flipped classroom: a modality for mixed asynchronous and synchronous learning in a residency program. West J Emerg Med. 2014;15(7):938-944.

16. Tainter CR, Wong NL, Cudemus-Deseda GA, Bittner EA. The "flipped classroom" model for teaching in the intensive care unit. J Intensive Care Med. 2017;32(3):187-196.

17. Khanova J, Roth MT, Rodgewrs JE, McLaughlin JE. Student experiences across multiple flipped courses in a single curriculum. Med Educ. 2015;49:1038-1048.

18. Michigan State University College of Osteopathic Medicine. Statewide Campus System https://scs.ms u.edu/.

19. Bloom BS. Taxonomy of Educational Objectives: The Classification of Educational Goals. New. York, NY: Longmans, Green; 1956.

20. Brightspace. Brightspace, Inc. About Desire to Learn (D2L. https://www.d21.com. Published 2016.

21. University of Michigan. Center for Research on Learning and Teaching (CRLT) Players. http://www.crl t.umich.edu/crltplayers.

22. Vittinghoff E, Shiboski SC, Glidden DV, McCulloch CE. Regression Methods in Biostatistics: Linear, Logistic, Survival, and Repeated Measures Models. New York: Brooks/Cole, Springer Science+Business Media, Inc; 2005.

23. IBM Corp. IBM SPSS Statistics for Windows, Version 22.0. Armonk, NY: IBM Corp. 